\title{
AN EPIDEMIOLOGICAL STUDY ON PATTERN OF SMOKING, ALCOHOL AND OTHER DRUGS CONSUMPTION AMONG FEMALE TEA PLCUKERS IN NUWARA-ELIYA, DISTRICT, SRI LANKA
}

\author{
Weerakoon AP, ${ }^{1}$ Jha RK, ${ }^{2}$ Wijeweera PR, ${ }^{3}$ Yapa Abeywardana C, ${ }^{4}$ Gamage W, ${ }^{4}$ Hearth \\ Gunaratne, ${ }^{4}$ Hearth $\mathrm{HMS}^{5}$
}

${ }^{1}$ Former Medical Officer, Maternal and Child Health, Nuwara eliya District, Sri Lanka and Research Officer, SAARC TB and HIVIAIDS Centre, Kathmandu, Nepal

${ }^{2}$ Dept. of Gastroenterology (Internal Medicine), Zhongnan Hospital, Wuhan University School of Medicine, Wuhan 430071, Hubei, PR China.

${ }^{3}$ Public Health Inspector, DPDHS Office, Nuwara-eliya, Sri Lanka

${ }^{4}$ Faculty of Medicine, Tribhuvan University, Kathmandu, Nepal

${ }^{5}$ Statistical and Planning Officer, DPDHS Office, Nuwara-eliya, Sri Lanka

\begin{abstract}
Introduction : Smoking and alcohol consumption among the estate population are considered to be high. However there is little documented evidence on the prevalence of smoking and alcohol consumption among female estate workers in Sri Lanka. The aim of this study was to find out the prevalence of smoking, alcohol and other dugs consumption among female estate workers and to find out factors associated with these habits.
\end{abstract}

Methodology : A community based cross sectional study was carried out with a sample of 928 females on a presumptive prevalence of $10 \%$ of alcohol users, using simple random sampling technique. Data was collected by trained field public health midwives using an interviewer administered questionnaire. Statistical analysis of data was carried out using SPSS version 11.

Results : The response rate was $97.8 \%$. Prevalence of smoking, alcohol and other drugs were $7.27 \%, 34.7 \%$ and $0 \%$ respectively. Among smokers, most smoked cigar (55\%), followed by Beedi (39\%) and cigarette (6\%). None indulged in dangerous drugs like Heroin and cannabis. Most consumed alcoholic beverage was toddy (64\%) followed by arrack (31\%). Seventy four percent of women stated that they consume alcohol because they were influenced by their husbands. A significant positive association was observed between smoking and (a)illiteracy $(p<0.05)(b)$ marriage $(p<0.05)(c)$ age more than 35 years $(p<0.01)$.There was a significant positive association observed between alcohol consumption and (a)illiteracy $(p<0.001)(b)$ marriage $(p<0.001)$ (c) parental drinking $(p<0.001)$.There was a significant positive association between the use of alcohol and dispute within the family $(p<0.001)$ as well as dispute with the neighbours $(p<0.01)$

Conclusion : One third of estate women consume alcohol and 7\% indulge in smoking, which is very much more than for the rest of the country. There is an urgent need for health awareness to be implemented in the estate sector to overcome this problem.

Keywords : Alcohol, smoking, estate women, Sri Lanka, prevalence

\section{Correspondence to}

Dr. Ajith Weerakoon

Former Medical Officer, Maternal and Child Health

Nuwara eliya District, Sri Lanka and Research Officer

SAARC TB and HIVIAIDS Centre

Kathmandu, Nepal

\section{INTRODUCTION}

Although women drink less than men, the number of women who drink is significant. Global estimates indicate that of the 15.1 million people who abuse 
alcohol or are alcohol dependent, 4.6 million are women. That means that roughly one third of alcoholics are women. ${ }^{1}$ There is indirect evidence indicating that alcohol consumption is increase in Sri Lanka. This is based on the increase number of Cirrhosis of the liver seen in hospital practice. According to hospital data chronic liver failure and cirrhosis mortality rates in year 2000 were 5.7 per 100,000 for males and 0.9 per 100,000 for women. ${ }^{2}$

The consumption of cigarettes and other tobacco productsandexposuretotobaccosmokearetheworld's leading preventable cause of death, responsible for about 5 million deaths a year, mostly in poor countries and poor populations. Latest estimates reveal that, of the nearly 4 million men and 1 million women who died, over 2 million men and 380,000 women were in developing countries ${ }^{(3)}$. About 250 million women in the world are daily smokers. About $9 \%$ of women in developed countries and $9 \%$ of women in developing countries smoke tobacco. In addition, many women in South Asia chew tobacco.

The tobacco industry promotes cigarettes to women using seductive but false images of vitality slimness, modernity, emancipation, sophistication, and sexual allure. In reality, it causes diseases and death. Tobacco companies have now produced a range of brands aimed at women. Most notable are the "women only brands". These feminized cigarettes are long, extra slim, with low tar and light colored.

Studies have shown that the prevalence of tobacco smoking in adult males, above 18 years of age, is high $(48 \%-63 \%)$ in Sri Lanka. Due to cultural inhibitions smoking is still uncommon in Sri Lankan females; the prevalence reported being less than $2 \% .{ }^{4}$

There are many on going programmes aimed at reducing alcohol, smoking and other drugs consumption in Sri Lanka. These programmes use various approaches. Some programmes are aimed at school children trying to prevent them from starting to drink. Some programmes are aimed at women teaching them how to cope with their husbands drinking. There are several programmes aimed at rehabilitating alcoholics and drug addicts. In spite of these programmes, consumption of alcohol, smoking and other drugs are on the rise.

The plantation population of Sri Lanka, numbering nearly one million in 2001, is concentrated in a geographically contiguous area in the highlands of Sri Lanka. They provide the main labour component of the tea industry. Tea is the principal agricultural commodity of Sri Lanka. Tea pluckers are almost exclusively women. The tea crop accounts for 223,000 hectares ( $10 \%$ of the total cultivated area of Sri Lanka) and employs 400,000 people or $16 \%$ of the total labour force. Tea plantations are concentrated in the Nuwara eliya district, which forms our main field study area.

Nuwar eliya district where most plantation workers live has consistently recorded an above average maternal mortality and infant mortality rates. The lower health status of the plantation population is also illustrated by their lower life expectancy at age one. Female life expectancy is lower than male life expectancy in Nuwara eliya district. The Indian Tamil population has the lowest literacy levels in the country. Only $66.9 \%$ of this population is literate, compared to $88.4 \%$ for the Sinhalese and $86.9 \%$ for Sri Lanka Tamil. Among all females in Sri Lanka, this group of plantation workers has the lowest literacy rate of $55.1 \%$. The widest gender gap in literacy among all ethnic groups in Sri Lanka is also seen within the plantation group.

Alcohol is the most prevalent addictive substance used in Sri Lanka and this practice has been in existence for centuries. Although, accurate estimates are not available for Sri Lanka plantation sector, it is very likely that the health, economic and social cost of alcohol is enormous. Drugs and alcohol may cause problems related to health (physical and mental) behaviors', family, work, money and law. Situation is worse when both partners of the family are indulging in alcohol consumption together. Tensions and arguments 
within the family are frequent. Usually in Sri Lankan scenario, children nourishment and education depend on mother's ability. So mother's behavior definitely adversely affects children nutrition and education.

Drugs and alcohol misuse can also cause problems for society at large. Widespread drugs or alcohol misuse leads to broken families and the neglect of children, who are the foundation of a country's strength and future.

Studies on alcohol, and other drugs use among females in Sri Lanka, especially plantation sector, are scarce. Hence this study was useful to achieve the following objectives.

To estimate the prevalence of alcohol and other drug consumption among female tea pluckers in the plantation sector Kothmale $\mathrm{MOH}$ area Sri Lanka.

To determine the impact of alcohol and other drugs consumption on the well being of families of these women.

\section{METHODOLOGY}

Study design: Community based cross sectional study was carried out among adult female tea pluckers residing in Kothmale $\mathrm{MOH}$ area, Central Province, Sri Lanka.

Study setting : Kothmale $\mathrm{MOH}$ area, Nuwara eliya district, Sri Lanka was selected for the study. It has a population of nearly 100,000 . $41 \%$ of its population is estate population.

Study Population : The study population consisted of female tea pluckers who fulfilled the following criteria.

Inclusion criteria : Adult women who are currently engaged in tea plucking and who are permanently residing in the study area.
Exclusion criteria : Women with a diagnosis (as confirmed by a diagnosis card or a clinic record) of any chronic illness, physical abnormality or mentally subnormal were excluded from the study. Women who refused to participate in the study. Women below the age of 18 years were also excluded from the study due to ethical reasons.

Sample size was calculated using the following formula ${ }^{5} \quad N=Z^{2} p(1-p) / d^{2}$

$\mathrm{N}=$ Sample size

$Z=$ value of 1.96 that corresponds to a confidence interval of $95 \%$

$\mathrm{d}=$ Level of precision -0.02

$p=$ Expected prevalence $-10 \%$

Non response rate $-10 \%$

Sampling procedure : The women of the study population were working in 13 estates. Using pay sheet as a sampling frame, 950 women were selected using random sampling.

Method of Data Collection : An interviewer administered pre coded structured questionnaire was used as a study instrument. Questionnaire was pre tested among the adult female tea pluckers in another $\mathrm{MOH}$ area. Data collection was carried out in a confidential place in the work place. Field Public Health Midwives (PHMM) was selected as field investigators to assist Principal Investigator in data collection. Field investigators were given a two days training on importance of assessing eligibility criteria and minimizing non response was emphasized. Ensuring uniformity during data collection by investigators was stressed. Ethical clearance for the study was obtained from Ethical Review Committee of Faculty of Medicine, University of Peradeniya, Sri Lanka. Analysis was done using the SPSS software package.

Measures taken to ensure quality of data : The following measures were taken to improve the quality of the data both at the designing stage and the implementation stage of the study. 


\section{A. Steps to minimize random errors}

An adequate sample of women was selected for the study. The sample size was calculated using a standard formula which estimates a population proportion with specified relative precision.

\section{B. Steps to minimize systematic errors}

\section{Selection bias}

The most recently updated sampling frames were used in drawing the study sample. The simple random sampling method was used to draw a representative sample from the study population and inclusion and exclusion criteria were clearly defined and strictly followed in order to minimize selection bias.

\section{- Non response}

Absenteeism of women was minimized by informing them through plantation management.

\section{Information bias}

Information bias occurs systematically owing to the following three sources, namely, variation in subject, instruments and observers.

\section{- Variation in subjects}

Data were collected within the familiar environments in the morning periods of normal working hours.

\section{- Variation in instruments}

Questionnaires were designed with much emphasis on its format to include operational and clear variables. Following measures also were taken to improve validity of questionnaire:

- $\quad$ Review of previous questionnaires used in local and foreign studies.

- $\quad$ Pre-test.

\section{- Variation in observers}

Observers were uniformly trained by the $\mathrm{PI}$ and a resource person on administering the questionnaire. They were adequately supervised during data collection.

\section{RESULTS}

The study included 928 tea pluckers with a nonresponse rate of $2.3 \%$. Non respondents were not different to those who completed the study. Seventy eight percent of women were literate, while $4.5 \%$ had received any school education. Among the study population a majority of women were married $(82 \%)$ while $12 \%$ of women were never married. It was observed that $64 \%$ of women were receiving a monthly income of 5000-10,000 S.L.Rs.

In the present study, study subjects' frequency of alcohol, smoking and other harmful drugs consumption was determined based on their response to the following.

(a) Ever consumption of above substance

(b) Consumption of substances during the past year

(c) Consumption of substance during the past 2 weeks.

Based on their responses they were assigned to one of the following three categories.

(1) Never/Abstainers- Never consumed

(2) Occasional users- Who had not consumed any form of substance during the two weeks preceding the interview, but had consumed during the preceding year.

(3) Current users- Who had consumed during the fortnight preceding the interview.

According to this classification, prevalence of smoking and alcohol is given in the Table 1. 


\begin{tabular}{|c|c|c|c|}
\hline Frequency & $\begin{array}{c}\text { Alcohol } \\
\text { consumption } \\
\text { (\%) }\end{array}$ & $\begin{array}{c}\text { Smoking } \\
(\%)\end{array}$ & $\begin{array}{c}\text { Tobacco use } \\
\text { (betel) }\end{array}$ \\
\hline Never & $\begin{array}{l}606 \\
(65.3 \%)\end{array}$ & $\begin{array}{l}861 \\
(92.8 \%)\end{array}$ & $\begin{array}{l}125 \\
(13.4 \%)\end{array}$ \\
\hline Occasional & $100(10.8 \%)$ & & $153(16.5 \%)$ \\
\hline $\begin{array}{l}\text { Regular } \\
\text { (current) }\end{array}$ & $\begin{array}{l}222 \\
(23.9 \%)\end{array}$ & $\begin{array}{l}67 \\
(7.2 \%)\end{array}$ & $\begin{array}{l}650 \\
(70.0 \%)\end{array}$ \\
\hline Total & $\begin{array}{l}928 \\
(100.0 \%)\end{array}$ & $\begin{array}{l}928 \\
(100.0 \%)\end{array}$ & $\begin{array}{l}928 \\
(100.0 \%)\end{array}$ \\
\hline
\end{tabular}

None of the women in the study population were indulged in other harmful substance. Eighty percent of women had started drinking before the age of 24 years. Similarly forty five percent of women had started smoking before the age of 24 years. Majority of women in ever consumption of alcohol group were in the 38-58 years age group.

\section{Type of alcohol and smoking (tobacco use)}

For individual who had consumed alcohol during the fortnight preceding the interview, the alcoholic beverage that had contributed the most amount of ethanol was considered as their favored alcoholic drink. Accordingly, most consumed alcohol beverage was toddy(64\%) followed by arrack(31\%) and beer (5\%). None had consumed wine and 'Kassippu' (locally made alcohol beverage). Among smokers, most smoked cigar (55\%), followed by Beedi (39\%) and cigarette (6\%).

\section{Association between alcohol consumption and selected socio-demographic variables:}

Table 2 describes the significant factors that are associated with alcohol consumption in Univariate analysis.
Table 2: Factors with significant association with alcohol consumption

\begin{tabular}{|ll|}
\hline Factors & Level of Significant \\
Illiteracy & $\chi^{2}=153 \mathrm{df}=1, p<0.0001$ \\
Married civil status & $\chi^{2}=44.6 \mathrm{df}=1, p<0.001$ \\
Parental drinking & $\chi^{2}=26.3 \mathrm{df}=1, p<0.01$ \\
\hline
\end{tabular}

\begin{tabular}{|c|c|c|}
\hline Drinking companion & Number & $\%$ \\
\hline Husband & 193 & 86.9 \\
\hline Alone & 09 & 4.1 \\
\hline Work mate & 11 & 5.0 \\
\hline $\begin{array}{l}\text { Family members } \\
\text { other than husband }\end{array}$ & 09 & 4.1 \\
\hline Total & 222 & 100.0 \\
\hline
\end{tabular}

According to Table 3, most common drinking companion was her husband

\begin{tabular}{ll|}
$\begin{array}{l}\text { Table 4: Most common reasons given by } \\
\text { women for consumption of alcohol }\end{array}$ \\
\hline Reasons for drinking & No \\
\hline Because my husband also dinks & 167 \\
\hline Because my parents also drink & 76 \\
\hline To keep company with friends & 06 \\
\hline To relive body aches after work & 156 \\
\hline To forget my worries & 178 \\
\hline
\end{tabular}

More than one answer was stated by the respondents.

Reasons for not drinking were also assessed. The common reasons stated by the women in the study were listed in table 5. 


\begin{tabular}{|ll|}
\hline Table 5: Reasons for not drinking \\
\hline Reasons for not drinking & No \\
\hline It costs too much money & 524 \\
Not good for the health & 129 \\
Upsets family & 328 \\
Can interfere with work & 222 \\
My husband does not like & 87 \\
\hline It goes against my religion & 12 \\
\hline
\end{tabular}

Fifty seven percent of ever drinkers stated that they had an alcohol outlet more than $5 \mathrm{Km}$ from their line room. Over all $80 \%$ of the ever drinkers felt that price of alcohol was either very expensive or expensive.

\section{Alcohol related social problem :}

\section{Table 6: Significant social problems}

associated with alcohol consumption

\begin{tabular}{|ll|}
\hline Factors & Level of Significance \\
Intra family dispute & $\chi^{2}=6.6 \mathrm{df}=1, p<0.05$ \\
$\begin{array}{l}\text { Dispute with } \\
\text { neighbors' }\end{array}$ & $\chi^{2}=10.7 \mathrm{df}=1, p<0.05$ \\
$\begin{array}{l}\text { Selling and } \\
\text { mortgaging } \\
\text { of household items } \\
\text { during past one year }\end{array}$ & $\chi^{2}=55.0 \mathrm{df}=1, p<0.01$ \\
\hline
\end{tabular}

\section{DISCUSSION}

This study provides meaningful information for the formulation of necessary policies and strategies for improving quality of life of the estate female workers. In addition, the findings of this study will also establish a baseline for future studies.

The low no response rate could be attributed to the management structure of the estate and also selecting females as field investigators (PHMM).
The main instrument in the study was an interviewer administered questionnaire. The validity of the data obtained through this instrument depends on the ability of the interviewer to elicit accurate information with minimal bias. The use of self administered questionnaire demand some level of education and skill from the respondent. In the present study only $78.2 \%$ of women were literate; therefore interviewer administered questionnaire is the most suitable.

Prevalence of alcohol consumption : It was found that in the present study $24 \%$ of adult female tea pluckers were current alcohol users. Previous studies done in Sri Lanka revealed very much lower prevalence.

Study done by Nugegoda et al (1996) found that less than $0.3 \%$ of female were consuming alcohol in rural area of Central Province in 1996. ${ }^{6}$ Study done in Gampaha district, Sri Lanka, about 10 years ago gives $8 \%$ prevalence among women. ${ }^{7}$

Compared to the previous studies done in Sri Lanka, in plantation sector, alcohol consumption among women were very high. Because of Sri Lankan cultural back ground in the rural set up many women remain abstain, but results of the present study may be a warning to policy makers and health care providers in the estate sector.

The highest prevalence of alcohol consumption was seen in the $38-58$ years age group which agree with the data of other similar studies. ${ }^{8,9}$

This is matter of concern as this includes most of the economically productive group of a work force. The higher percentage, seen in working age groups especially among women emphasize the importance of starting more preventive activities directed at work places. Human Development Trust which promotes health and other welfare activities in the plantation sector should provide more substance abuse prevention programme targeting especially on these women. 


\section{Prevalence of smoking and tobacco use : Due}

to cultural inhibitions, smoking is still uncommon among Sri Lankan females, the prevalence reported being less than $2 \%$ among adult females. ${ }^{4}$ But in the present study prevalence of smoking among adult tea pluckers is $7.2 \%$ which is much higher than the previous studies.

But compared to the prevalence rate of other neighboring countries this figure is low. The results of WHO survey indicate that the overall prevalence of daily smoking among women in Nepal was $62.4 \% 10$ In an urban survey conducted during 1992-1994 in Mumbai, India $57.5 \%$ of women in the age group of 35 years and above were current tobacco users, almost all of smokeless tobacco (only $0.4 \%$ smoked). Another study revealed beedi and cigarette smoking is high (at least 30\%) among women in Bihar and the northeastern states. Policy decisions taken in Sri Lanka in recent years to stop tobacco promotion and prohibition of smoking at public places may have influenced the declining trend of tobacco smoking in the recent past.

Although the majority of women in study population did not smoke, $70 \%$ of estate workers were regular betel- quid chewers including tobacco in betel -quid chewing.

\section{Association between alcohol consumption and other variables : A significant finding in the present} study was that there was an association between literacy and alcohol consumption among female tea pluckers. Females with less education were more likely to have consumed alcohol compared to females with better education. The percentage of currently married females in the present study was $82 \%$. There was a statistically significant positive association between ever consumption of alcohol and marriage. Married women tend to drink more than the currently not married women. The influence of husband may be the cause for this association. The study revealed that family dispute within the family and with neighbor was high in estate sector (37\% and $21.3 \%$ respectively).
Study done by Nugegoda et al at rural community in Kandy district, Sri Lanka found that much lower prevalence $(6.3 \%$ and $8.7 \%)$ respectively ${ }^{(6)}$. The present study observed that there was a very high statistically significant association between alcohol consumption of females and family disputes. This study also revealed that parental drinking is significantly associated with women consumption of alcohol. These findings are consistent with those seen in studies conducted in Sri Lanka. ${ }^{6}$ This can be the results of either a genetic factor or an environmental influence. This study has some drawbacks. None of the study participants stated that they had consumed illegal substances like heroin, cannabis, and alcoholic beverages. The nature of the study instrument (interviewer administered questionnaire) might have influenced the answering of these issues. Because of the traditions of the Sri Lankan culture, the subjects may not have given the correct information about the use of illicit substance. A self administered questionnaire would have been better option.

\section{ACKNOWLEDGEMENT}

The authors like to express sincere thanks to National Dangerous Drugs Control Board Sri Lanka, for providing funds for this study.

\section{REFERENCE}

1. U.S Department of Health and Human Services, Office for substance abuse prevention 1991.

2. Ministry of Health (2000), Annual Health Bulletin, Colombo.

3. World Health Organization (2003). Neglected Global epidemic: three growing threats, The World Health Report. Geneva, WHO.

4. Randeniya, B., Weerasooriya, W.A.J., (1989). Smoking patterns in Sri Lanka, Colombo, National cancer control program.

5. Laweangas K, Lemeshow S. (1991) Sample size determination in health studies. A practical manual. WHO. 
6. Nugegoda D.B., (1996). A pattern of alcohol consumption in rural community in Kandy District. Unpublished data.

7. Patmeswaran A (1997). Pattern of alcohol consumption in Gampaha district. MD Thesis, PGIM, Colombo.
8. Rathnapala N, Alcoholism a sinhalease village. Dehiwala, Sarvodaya Research Institute

9. Perera B, Fonseka P. (1997) Epidemiological aspects of alcohol consumption in a semi-urban community in Southern Sri Lanka, Galle Medical Journal; 1(2) 1620.

10. World Health Organization (1997) Tobacco or Health, A global status report. 